\title{
Technology-enhanced learning in Asia: New educational possibilities for the tomorrow's doctors and tomorrow's cures
}

\author{
Md Anwarul Azim Majumder ${ }^{1}$, Md Sayed Shehran Azim ${ }^{2}$, Sayeeda Rahman ${ }^{3}$ \\ ${ }^{1,3}$ Lecturer, Department of Clinical Sciences, School of Medical Sciences, University of Bradford, \\ Bradford, UK. ${ }^{2}$ Student, Department of Mechanical Engineering, University of Leeds, UK. \\ 'Today's learners have progressively embraced more technology as learning tools, and \\ have advanced past traditional forms from the twentieth century. Lectures are now \\ podcasts, textbooks are now e-books, and pharmacopeias are web-based applications \\ (apps). However, integrating new technology into the classroom can be challenging, with \\ the varying levels of sophistication in both the learners and the educators'. ${ }^{\prime}$
}

Medical education during the past decade has witnessed a significant increase in the use of educational technology in response to digital revolution and advances in information and communication technologies (ICT). Medical students in developed and developing countries are now accustomed to technology-enhanced learning. They are referred to as the 'YouTube generation', 'Generation Y', 'Millennial learners', 'Generation Next', and 'Net Generation'. 1,2 Medical educators are also increasingly utilizing technology to teach students. Universities of some developed countries are already teaching/training their medical students with hi-tech methods (Box 1). ${ }^{3}$ The 2011 survey by the Association of American Medical Colleges reported that 86 out of 90 medical schools and all 64 teaching hospitals used simulations to train medical students. ${ }^{4}$

Medical schools in developing countries are still struggling with the effective use of educational technology to bring desired changes in medical education. ${ }^{5}$ However, some of the medical schools in the region are now taking leading and pioneering roles in the process of adopting technology-enhanced learning (Box $2) .^{6-8}$ As technology is expected to evolve and become further integrated into peoples' lives, medical schools in Asian countries require substantial investment of resources (people, facilities, money) to open new possibilities and frontiers for effective teaching, learning and research, and uplift the standard of health care in the region.

Two methods of technology-enhanced learning have become more popular to teach and train medical students and other health professionals: simulation technology and online distance education. Simulation is now considered a valuable educational tool in undergraduate medical education and is increasingly being used to teach/train low frequency events that require high acuity (e.g., emergency procedures), and irreversible procedures (e.g. surgery). ${ }^{4,9,10}$ Simulation technologies encompass diverse products including computer-based virtual reality simulators, high fidelity and static mannequins, plastic models, live animals, inert animal products, and human cadavers. ${ }^{10}$ Two methods of simulation technology are widely used in medical schools: mannequin simulation and screenbased simulation. ${ }^{4}$ The most common type of simulation equipment is the full scale mannequin, most

Box 1: The New York University School of Medicine: innovative teaching tools ${ }^{3}$

- The Virtual Microscope is used in the pre-clerkship curriculum in place of the traditional microscope.

- WISE-MD (Web-based Initiative in Surgical Education) is a tool for surgical education, used in the Surgery clerkship at the NYU School of Medicine. Wise MD provides a computerized linear narrative of patient illness and patient-physician interaction from the patient's first visit with his or her physician, through the diagnostic process, into the operating room, through the laboratory studies and pathology, and finally to the postoperative visits.

- ALEX (Advanced Learning EXchange) is a Sakai-based Learning Management System that serves as a central resource for online medical education content and computer-based learning activities.

- Online learning modules are used throughout the four years to teach and reinforce specific curricular topics.

- The BioDigital Human is an interactive online virtual human body. It allows students, using 3D glasses, to view life-sized digital content displayed on a projector screen in the anatomy lab, and was showcased as a part of TedMED 2013.

Correspondence: Dr Md Anwarul Azim Majumder, Lecturer, Department of Clinical Sciences, School of Medical Sciences, University of Bradford, Bradford BD7 1DP, UK. Email: a.a.majumder@bradford.ac.uk. 
Box 2: Technology-enhanced learning in medical schools of Asia

\section{National University Hospital, Singapore ${ }^{6}$}

In Asia, Singapore was the first country to integrate advanced simulation facilities for nursing education, at the Critical Care Nursing Simulation Laboratory of the National University Hospital (NUH), which opened in 2007. The most integral component of the laboratory is a high-fidelity simulation mannequin, which can simulate almost all critical medical conditions. Students gain experience in critical skills such as airway management, immobilization, basic and advanced life support, and the ability to safely practice their clinical skills prior to interacting with real patients, thus greatly improving the quality of care that they provide. Moreover, in the laboratory, doctors and nurses are trained alongside one another, promoting effective multi-professional education.

Far Eastern University Institute of Nursing, Philippines ${ }^{6}$

Another example of a high-fidelity simulation laboratory from Asia is the Virtual Integrated Nursing Education Simulation Laboratory (VINES) at the Far Eastern University Institute of Nursing in the Philippines. The VINES integrates hospital-like qualities into their laboratory, as well as high-fidelity mannequins for safe and controlled environments for its student nurses.

\section{SRM University, India ${ }^{7}$}

The SRM/STRATUS Centre for Medical Simulation, India is the largest Simulation center in South East Asia established in 2011. The centre is a highly advanced educational centre which utilises state-of-the-art technology including computer controlled patient simulation system and individualised task trainers. In the last one year, the Centre have conducted different life saving courses, targeted at a multi spectrum audience, including Doctors, Nurses, Physiotherapists, Medical students, CRRIs, Dentists and Fire personnel. A total of 1599 students have been trained in the Center in the last one year.

\section{National University of Singapore 8}

Students at the National University of Singapore's (NUS) Yong Loo Lin School of Medicine could be dissecting 3D holographic cadavers in three years' time. The medical school is aiming to be the first in the world to use virtual reality simulation on a full scale, according to Associate Professor Suresh Pillai, director of NUS' Centre for Healthcare Simulation. The centre is working on an interactive cadaver project with the Keio-NUS Connective Ubiquitous Technology for Embodiments Centre and a pilot project involving a small group of students will be carried out at the end of 2017.

often a computerized adult and screen-based simulation allows learners to interview, examine, diagnose, and treat patients in realistic clinical scenarios. Examples of screen-based simulation include virtual patients, virtual environments, or physiologic simulations.

Online education has increased the training opportunities for working professionals, as well as students and providers in remote and rural locations. ${ }^{9}$ This approach can 'help address issues of educational equity and social exclusion, and open up democratic and accessible educational opportunities', especially for the healthcare students in developing countries. ${ }^{11}$ The demand for 'transnational higher education' (learners are located in a country different from the one where the awarding institution is based) is on rise in Asian countries (excluding China) ${ }^{12}$ and it is estimated that the number of students will be more than 480,000 by
$2020 .{ }^{13}$ This may help in the long run to minimize the acute 'global healthcare talent gap' and the 'critical shortage' of personnel in the health workforce, particularly in the world's poorest countries (Box 3). ${ }^{9}$

The Higher Education Funding Council for England (HEFCE) identifies three levels where technology could enhance learning and teaching: Efficiency (make existing processes more effective in relation to cost, time, scalability or sustainability); Enhancement (improve or enhance existing processes/outcomes) and Transformation (radically transform existing processes). ${ }^{14}$ Important benefits realized by using technology to train medical students suggested in the education literature include: safe, controlled environments that eliminate risk to patients; accessible learning situations that are rare in real life; opportunities to practice rare and critical events; learner control of the

Box 3: Medical education goes digital ${ }^{9}$

University of Washington's Department, USA

The University of Washington's Department of Global Health uses distance learning technologies for low-resource settings through an initiative called eDGH. It runs e-learning programs in more than 30 countries and delivers classes to students in many of the world's poorest places. Its flagship course on Clinical Management of HIV now reaches over 1,000 students globally each year.

Harvard Medical School, USA

A Harvard Medical School-affiliated NGO called HAIVN runs a video conferencing platform that connects HIV specialists in top Vietnamese hospitals with frontline community health workers. It pioneered the use of video conferencing for remote training in healthcare; HAIVN now operates in more than 20 provinces in Vietnam. 
'In response to the new technology, and changes in student habits, medical schools are quickly implementing sweeping curriculum reform and "flipping the classroom." It's now assumed that students will absorb the basics on their own, at their convenience, using smartphones, tablets or web-based lectures and interactive learning modules. Then they come back to school to work out problems they've encountered or apply what they've learned. ${ }^{15}$

educational experience; repetition and deliberate practice; freedom to make and learn from mistakes; instruction tailored to individual or group needs; and standardization of instruction and assessment. ${ }^{4,6,10}$ Although many students' experiences with education technology have been positive, there are challenges to face when integrating technology into the classroom. Challenges for implementing technology include: cost, faculty reluctance, lack of foundational knowledge, technological distractions, and cheating and plagiarism. ${ }^{1}$ Cost is the greatest barrier to implement technology enhanced teaching in medical schools in Asian countries. While some faculty members are fully on board with evolving methods of instruction, others feel more comfortable with traditional teaching styles and may be reluctant to change. ${ }^{1}$

Flipped classrooms have gained a lot of popularity in medical education over the last few years. It refers to an approach to teaching where the traditional class time and self-study activities are reversed or 'flipped'. ${ }^{15,16}$ The flipped classroom is a form of blended learning in which students learn new content online by watching video lectures (pre-recorded) or undertaking assigned reading and activities first, then the lecture time is being used for more active learning activities (e.g. interactive discussion, problem-solving and other activities with the teacher). Though there are challenges in implementation, flipped classrooms have a number of advantages: they cater individualized education and training, incorporate evidence-based teaching techniques, optimizing teachers' time, increase student-teacher interactions, and improve students' self-directed learning techniques. ${ }^{16}$

On-line social media (Twitter, Facebook, Doximity, Sermo, YouTube, Flickr, Google+, LinkedIn etc.) is now being increasingly used by doctors and medical students, ${ }^{17}$ even in teaching and learning. ${ }^{1}$ Social media describes web-based applications that allow people to create and exchange content, which include blogs and microblogs (such as Twitter), internet forums (such as doctors.net), content communities (such as YouTube and Flickr), and social networking sites (such as Facebook and LinkedIn). ${ }^{18}$ As uses in medicine grow, these media can pose risks for medical students and health professionals and therefore an awareness of the implications on ethics, professionalism, relationships, and profession need to be highlighted. ${ }^{15}$ Inappropriate use of social media can have serious implications - it 'can potentially damage personal integrity, doctorpatient and doctor-colleague relationships, and future employment opportunities'. ${ }^{17,18}$ Practical guidelines should be developed by medical councils, associations and other authorities to assist doctors and medical students to continue to enjoy the online world, while maintaining professional standards and medical professionalism. ${ }^{18}$
Medical educators and policy makers need to consider the notion of 'cultural lag' and the 'technological gap' in an Asian context ${ }^{19}$ in utilizing and designing technology-enhanced education and training. The effective use of technology depends on faculty readiness to use sophisticated and high-fidelity devices in virtual reality environments. Teachers should be trained to operate simulators and other devices (including on-line learning techniques) and to employ the technologies to facilitate teaching and learning. The Centre for Medical Education and other related organizations should develop competency-based faculty training in the use of advanced educational technologies. Moreover, medical schools should take responsibility to help students and teachers to develop 'digital literacy' and 'digital professionalism'.

\section{References}

1. Bahner DP, Adkins E, Patel N, Donley C, Nagel $\mathrm{R}$, Kman NE. How we use social media to supplement a novel curriculum in medical education. Med Teach 2012;34:439-44.

2. Sandars J, Morrison C. What is the Net Generation? The challenge for future medical education. Med Teach 2007;29:85-8.

3. NYULMC Division of Educational Informatics. Courseware and Applications. http:// dei.med.nyu.edu/courseware (accessed 30 Dec 2014)

4. Association of American Medical Colleges, Medical Simulation in Medical Education: Results of an AAMC Survey. Washington, DC: AAMC, 2011.

5. Houshyari $\mathrm{AB}$, Bahadorani $\mathrm{M}$, Tootoonchi $\mathrm{M}$, Gardiner JJ, Peña RA, Adibi P. Information and Communication Technology in Medical Education: An Experience from a Developing Country. J Pak Med Assoc 2012;62(3 Suppl 2): S715 .

6. Kong L. Integrating High-Fidelity Simulation in Nursing and Medical Training for Seamless Care. http:// www.cybertherapyandrehabilitation.com/2014/0 5/integrating-high-fidelity-simulation-nursingmedical-training-seamless-care/ (accessed 30 Dec 2014)

7. SRM University. SRM Stratus Centre for Medical Simulation. http://www.srmuniv.ac.in/ ms/index.htm (accessed 30 Dec 2014)

8. Teng A. NUS Medicine students to use 3D cadavers in three years' time. http://linkis.com/ SBr1M (accessed 30 Dec 2014) 
9. Greene W. Emerging Market Medical Education Goes Digital. http:// techonomy.com/2015/03/emerging-marketmedical-education-goes-digital/ (accessed 30 Dec 2014)

10. Cook DA, Hatala R, Brydges R, Zendejas B, Szostek JH, Wang AT, Erwin PJ, Hamstra SJ. Technology-Enhanced Simulation for Health Professions Education A Systematic Review and Meta-analysis. JAMA 2011 Sep 7;306(9):978-88.

11. Gulati S. Technology-Enhanced Learning in Developing Nations: A review. Int Rev Res Open Distance Learn 2008;9(1):1-16.

12. Ziguras C. Educational technology in transnational higher education in South East Asia: the cultural politics of flexible learning. Educ Technol Soc 2001;4(4):8-18.

13. Global Alliance for Transnational Education. Demand for Transnational Education in the Asia Pacific. Washington: Global Alliance for Transnational Education, 2000.
14. Higher Education Funding Council for England (HEFCE). Enhancing learning and teaching through the use of technology: A revised approach to HEFCE's strategy for elearning. http://www.hefce.ac.uk/pubs/ year/2009/200912/\#d.en.63806 (accessed 30 Dec 2014)

15. Mahapatra J. Medical Education's Digital Revolution. http://www.epmonthly.com/features/ current-features/medical-education-s-digitalrevolution/ (accessed 30 Dec 2014)

16. Moffett J. Twelve Tips for Flipping the Classroom. Med Teach 2015;37(4):331-6.

17. Mansfield SJ, Morrison SG, Stephens HO, Bonning MA, Wang SH, Withers $\mathrm{AH}$, et al. Social media and the medical profession. Med $J$ Aust 2011;194(12):642-4.

18. General Medical Council. Doctors' use of social media. London: GMC, 2013.

19. Majumder MAA. Issues and Priorities of Medical Education Research in Asia. Ann Acad Med Singapore 2004;33:257-63. 